\title{
Codes of Ethical Conduct: A Bottom-Up Approach
}

\author{
Ronald Paul Hill $\cdot$ Justine M. Rapp
}

Received: 18 January 2013/Accepted: 12 December 2013/Published online: 1 January 2014

(C) Springer Science+Business Media Dordrecht 2013

\begin{abstract}
Developing and implementing a meaningful code of conduct by managers or consultants may require a change in orientation that modifies the way these precepts are determined. The position advocated herein is for a different approach to understanding and organizing the guiding parameters of the firm that requires individual reflection and empowerment of the entire organization to advance their shared values. The processes involved are discussed using four discrete stages that move from the personal to the work team and to the unit to the full company, followed by the board of directors' evaluation. The hoped-for end product is dynamic, employee-driven, codes of conduct that recognize the systemic and farreaching impact of organizational activities across internal and external stakeholders. Operational details for and some issues associated with its implementation are also provided.
\end{abstract}

Keywords Code of conduct - Employee-driven approaches · Bottom-up development

\section{Corporation, Be Good! Frederick (2006)}

That managers and employees are capable of both ethical and unethical behaviors due to individual and internal

R. P. Hill

Villanova School of Business, 800 Lancaster Avenue, Villanova, PA 19095, USA

e-mail: Ronald.hill@villanova.edu

J. M. Rapp ( $\square)$

School of Business Administration, University of San Diego,

5998 Alcalá Park, San Diego, CA 92110, USA

e-mail: jrapp@sandiego.edu corporate culture factors cannot be denied (Ashforth and Anand 2003; Treviño and Weaver 2003; Treviño et al. 2006). Over the last decade, as diverse organizational stakeholders began exerting more pressure on firms to eliminate unethical conduct, the field of management has witnessed a proliferation of research on ethics and ethical behavior in organizations (Elango et al. 2010; Gopalakrishnan et al. 2008; O'Fallon and Butterfield 2005; Treviño et al. 2006).

However, recent ethical failures, as well as continuous ethical challenges that organizations face, have led scholars to conclude that predicting ethical dilemmas is difficult a priori: "It is only, when we look back on our conduct over the long run that we may find ourselves guilty of moral laxity" (Geva 2006, p. 138). What underlies this particular situation is the inability of organizational elites to monitor and implement initiatives within today's complex business entities (Martin and Eisenhardt 2010; Uhl-Bien et al. 2007). Accordingly, more dynamic approaches to business ethics is needed, one that spans "both the individual and organizational levels" of concern (Gopalakrishnan et al. 2008, p. 757).

As a consequence and in reaction to neoclassical economics, managers and their employees are expected to go beyond dictates imposed by the law and marketplace to fulfill larger responsibilities (Stark 1993). This expectation is accomplished through adoption of a stakeholder perspective that is infused with empathy for people, groups, and communities that may be impacted by the actions of business firms (Nash 1981). For-profit entities must broaden their missions so that their overall contributions to society are factored into their strategies to achieve this level of success, with the inclusion of noneconomic goals as an important component (Andrews 1989). The end result is shared moral culture that engenders trust within and 
among the constellation of individuals and organizations that make up their interactive system (Feldman 2007).

Therefore, the main purpose of this paper is to explore how ethical behavior in businesses is driven by individual actions and interactions, and how it is subsequently amplified through team, unit, and ultimately organizational actions. While the emphasis is on the importance of individual behavior and "bottom-up" dynamics, we recognize the important role top leaders play in this process. More specifically, we argue that business leaders represent a crucial element in this process, since they are responsible for conditions that enable ethical behavior to occur, and, as importantly, for removal of obstacles to ethics development in the organization.

\section{Current Practices}

At its most fundamental level, the purpose of codes of ethics is to help managers to avoid hazards associated with the immoral actions (Rosthorn 2000), and reap rewards that emanate from moving toward a moral ideal (Garcia-Marza 2005). In a study analyzing thirty-nine ethics codes by Fortune 500 companies (Sanderson and Varner 1984), the authors found the predominance of content related to issues surrounding federal laws $(75 \%)$, conflicts of interest (70\%), and political contributions (72\%), with the remainder addressing concerns related to customers, accounting records, and antitrust issues. The most notable finding from this assessment, however, is the purely lawbased or legal themes in the articulation of these codes of ethics.

However, scholarship has revealed that few businesses have created adequate processes for uncovering and articulating wider values (see Nash 1981). For example, Schwartz (2002) found a lack of consistency and standards among existing ethical codes, calling for a systematic approach in code development addressing the inclusion of six fundamental moral standards (see also Zadek 1998). Irrespective of this call, such oversight is exacerbated by internal cultures that value traditional markers of success originating with top management (Chonko et al. 2002).

A second predominant concern regarding the majority of codes of ethics within organizations is the engrained topdown structure of implementation. As such, executive dictated approaches disproportionately favor positions of organizational elites relative to the majority of employees who operate in the proverbial trenches. As a result, managers often attempt to guide ethical conduct by eliciting a set of moral codes that are presented to rank-and-file workers as given rather than negotiated (Feldman 2007). These codes of ethics, along with written policies and statements, offer little helpful guidance (Badaracco and
Webb 1995), and they typically are viewed as too broad and too superficial (Andrews 1989). They also may fail to grasp that norms of behavior do not implement themselves (McNamee and Fleming 2007), and that ethical expectations not well integrated into managerial decision-making are unlikely to have much impact (see Geva 2006).

Chonko et al. (2002) summarized the codes of conduct-ethics training-internal evaluation continuum as: (a) primarily reactive rather than proactive, (b) short-term oriented, (c) descriptive versus reflective, and (d) focused on individual behavior over collective impact. As noted, explanations for shortcomings are located in faulty reward systems that stem from leadership failure to advocate for moral principles. However, problems are as likely to originate in a lack of understanding of the dynamic, interactive, and systemic nature of organizational life (see Frederick 1995, 1998). In this regard, the development of a code of ethical conduct should create dialog that values contributions of all involved parties and recognizes the overlapping and competing interests and actions that lead to inevitable conflicts over resource allocations (Hill et al. 2007).

This background shows the importance of participation in the development and operationalization of moral standards for healthy ethical climates in businesses (also see Schwartz 2002). In this vein, a code of ethics must orient participants to ways in which idiosyncratic self-interests and altruistic tendencies drive behavior as they intersect with the organizational power bases, internal mores, and conflicting objectives that make up bioeconomic systems (Hill and Watkins 2009). Employing Ethical Climate Theory as a frame, this "mosaic" includes beliefs, attitudes, intentions, and behaviors that capture the complexity associated with workings of companies (Martin and Cullen 2006). To this end, developing a code of ethics must build from persons to groups to firms so that differences in values are uncovered and appropriately addressed (Nash 1981).

As a consequence, we advocate for a bottom-up approach in the development of organizational ethics codes, as scholarship finds that many formal statements of values are ignored unless they are the product of the company as a collective (DuFrene 2001; Nielsen and Massa 2013). Of course, this call has occurred previously and as a way to create co-ownership of the resulting ethical statements and enhance worker compliance (Brakel 2007). Such processes are built upon the belief that "a sense of moral rightness comes not from the indoctrination of abstract principles, but from attunement to the way in which moral beliefs and practices must be rooted naturally in the very conditions of human existence" (Buchholz and Rosenthal 2001, p. 25). Accordingly, we seek to add to this conversation by advancing an easy-to-operationalize conceptual framework outlining both the processes involved 
and potential considerations in undertaking such a bottomup approach to code development.

\section{Conceptual Development: A Bottom-Up Approach}

The Process

In reaction to either perceived or real difficulties in evaluating a universally understood and practiced code of ethics (DuFrene 2001), this paper explores an alternative that seeks to empower members of organizational communities to reflect on and express individual and joint moral aspirations for firms. Our conceptual development favors an "ascendant" rather than "descendant" approach as described by Enderle (1996, p. 51) in his plea for discussions "at all levels of economic actors." We believe this discussion to be a necessary continuation of and a contribution to growing literature asking for examination of the relationships between employee and management (Graen and Scandura 1987).
The process put forth here begins with exploration and development of personal codes of conduct that influence workers' relationships to their job functions. Next, formal groupings of employees come together to negotiate moral ideals that they would hold each other accountable for and that drive combined efforts for professional success. The subsequent task includes cross-group discussion and cooperation that further refines their ethical mandates, as consensus-building continues to permeate across business units. The final step is presentation to the governing board for ratification and final approval.

Figure 1 provides a visual representation consistent with negotiations permeating the entire company. In this illustration, there are four layers in the firm hierarchy whereby associated teams interact laterally until all organizational layers have codes fully vetted. When lateral negotiations are completed, the interactions move vertically with the same expectations for conclusion. Final outcome should be a worker-specified and approved code of ethics that considers the systemic impact of firm activities on all constituencies.

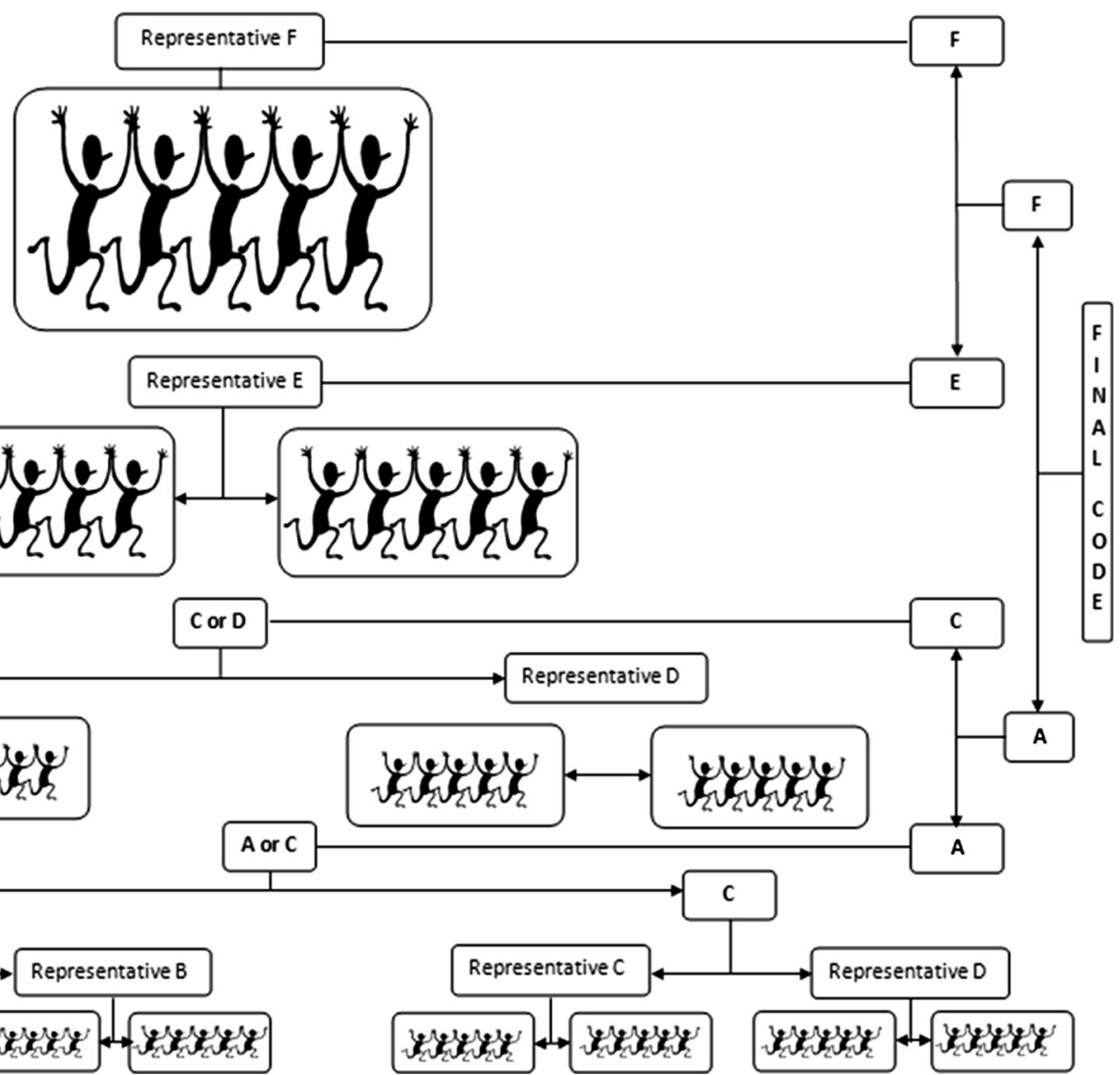

Fig. 1 Visual representation of complete audit 
The Role of Third-Party Consultants

One of the most integral components within a bottom-up development process is to establish the role for a trusted third-party or consultant to support various corporate units as the process moves up the organizational hierarchy. Through the four stages, the role of either moderators or mediators are integral to aiding the completion of the most appropriate and relevant codes of ethical conduct. While extant scholarship on group dynamics often specifies a separation of roles within groups (Strijbos et al. 2004), the process outlined here provides a higher likelihood of emotional connection to issues at hand, as well as a substantially larger stake in their successful usage. Thus, a third-party consultant trained in group negotiations and familiar with the industry at hand is needed to serve as external control (see Fisher 1972).

In stages one and two, we suggest the need for moderation, led by third-party individuals who are charged to monitor discussions, ask critical questions, and seek the opinions of others (de Wever et al. 2008), thus playing a significant role within early stages of code development. In addition, the moderator is only to facilitate conversation and aid in developing the most appropriate end product, not to engage in content creation or influence in company decisions (Fisher 1983). This final tenet is necessary, as the code of ethics developed from this process must always be the result of employees' deliberations, with no undue influence by external constituents.

Alternatively, we suggest the use of mediation within stage three, as significant levels of disagreement and contradiction will likely be encountered, when diverse business units are together (Gower 2003). As an alternative to the role of a moderator, a mediator must be in tune with the full range of acceptable agreements for the organization and employ "expertise in facilitating acceptable compromises or in imposing fair solutions" in order to actively facilitate negotiations (Fisher 1983, p. 304). Regardless, the mediator must assist interactions among internal parties, but s/he should not have authority to impose a final outcome (Wall et al. 2001), again solidifying the importance of employee dictated code creation.

\section{Stage One: Individual Reflections}

In many ways, the first step is likely to be very difficult for participants. Many adults are unlikely to have considered the ethical prohibitions and expectations that haunt or guide them in their personal and professional lives (see Hill et al. 2007). Such directives have taken-for-granted quality, making them sacrosanct and above reflection or comment. The majority of these precepts have their foundation in early periods of learning, morphing into an amalgamation of ways of thinking and behaving that are implicitly or explicitly taught by relatives, teachers, coaches, peers, coworkers, and other role models (Nurmi 1993).

Given the nature of these discussions, the best way to begin is with a framing conversation. These frames often originate with western philosophers who advocate thinking and behavior that seem remote in language and directives. Even more recent figures with a modern approach such as Rawls (1971) are considered difficult to understand much less implement. The greatest concern centers on the perceived lack of understanding regarding the profit-seeking purpose of the corporation, with the implied limitation that ethics and organizational success are somehow antithetical (Nash 1981).

Regardless of background, most people are aware of the Ten Commandments, even if they are unable to recite more than a few of them. Such moral dictates are well-recognized, easily articulated, and simple to understand, and they are a springboard into the larger conversation about professional ethics. Their usage in this situation may provide some relief from fears that this exercise will be too esoteric or too difficult to comprehend. Thus, the bottomup process begins with the request that each person prepare his or her set of commandments.

In doing such, individuals should seek to list all of the moral principles guiding their lives (both personally and professionally) in as simple a form as possible and without judgment (Kruckeberg 2000). At this early stage, the only instruction is to use no more than one concise sentence for each principle and to aim for ten items in order to avoid superficial reflection. Initial focus on individual mores may create enthusiasm for the process, since it lends credence to the belief that each person is an essential element in the formation of the firm's moral parameters.

In addition, participants are asked to notice whether their listings mostly contain prohibitions (must not do) or mostly responsibilities (must do) or an approximately equal number of both types of ethical parameters (Stevens 2008). This recognition is designed to make them aware of natural tendencies. In the former case (must not do), such dictates are reactive, causing people to avoid doing something in response to natural triggers. For instance, a salesperson might suggest that it is inappropriate to provide a knowingly false delivery date, even though telling the truth might cause the use of a different vendor. In the latter case (must do), mandates are proactive, leading individuals to follow guidance prior to circumstances arising. For example, managers could decide in advance that all terminations must be handled as they would like family members to be treated. Such reflection allows individuals to understand personal prescriptions and how best to respond to moral dictates. A combination of prohibitions and responsibilities is advised, but not required. 
Role of Moderators Personal mores must undergo further analysis by third-party moderators before entry into stage two. After self-evaluations are completed, moderators look at individual sets and provide feedback for possible revisions. Rather than making judgment, their recommendations take the form of analyses of the underlying logic, relevance to the job tasks performed, and one's likely ability to follow them under the most conditions. Feedback comes in the form of critical questions concerning logic, asking whether components of commandments focus behaviors in ways that are consistent with intended meanings. Typical questions to emerge should focus on relevance to the work environment and product, and one's ability to operate within the dictated parameters while still maintaining important relationships. The role of moderator is to seek revisions of commands, moving codes from ambiguous to contextually specific, and personal to focus on professional conduct.

The review process in stage one is iterative and continues until both individuals and third-party consultants are satisfied fully with the end result. The final product for everyone is a refined list of personal commandments that they may place on laminated, pocket-size cards that can be referred to when ethical issues occur during decisions.

\section{Stage Two: Work Team Discussions}

The second step moves individual focused discussions to group exchanges focused on creation of moral parameters that work teams agree to follow. Stage two operates best if groupings are limited to individuals who interact with one another on a regular basis and exist at the same organizational level to avoid problems associated with trust and status differences (Zaheer et al. 1998). Thus, salespeople collaborate with other salespeople involved with similar products or in a peer division, while their managers develop joint ethics statements along with other sales managers. Teams are optimally between five and eight members so that everyone has an opportunity to be heard and to increase participation on a per person basis (see Wheelan 2009 for support on smaller versus larger group sizes). ${ }^{1}$ No one who occupies a supervisory role over involved employees may join their conversations so as to avoid fears about retribution for comments made.

Role of Moderators Contrary to stage one, moderators play a consistent role throughout the entirety of stage two. Accordingly, there are four distinct instructions given by

\footnotetext{
${ }^{1}$ Business units larger than ten people may split apart at the start of the process and join together later when sufficient agreement and understanding is reached.
}

moderators to insure that the process is productive and does not needlessly hurry or delay the final outcome. First, each individual should discuss their personal commandments with the group to the extent they may impact interactions with the team members. Any criticisms or judgments of individuals or mores are not allowed, with an emphasis placed instead on trying to find ways to bring together all ideas into a cohesive whole that represents a shared vision of workplace activities and ethical issues. Other team members must limit their interactions during this phase to clarifying questions, with the moderator protecting integrity of the discussion.

The second directive provides a frame for understanding how to work toward the end result. Participants are asked to consider many interrelated ideas inspired by research of business ethicist Patricia Werhane. Accordingly, moderators should guide individuals to take a systemic view of their work together, recognizing that employee's actions and reactions impact professional lives of others around them in profound ways (Werhane 2002). Individuals also must recognize that their combined influence goes beyond teams or company boundaries, suggesting different answers to the question, "Why should I do the right thing?" (de Colle and Werhane 2008). Combined thinking should be driven by moral imagination that may reject existing mental models and moral conflicts for new commandments that include unique and untested approaches.

The third instruction addresses the final outcome of their deliberations. Simply stated, the group must come up with a set of ethical statements that they would agree to display publically and hold each other responsible for during the pursuit of their various job functions. The most important condition is that all team members should abide by the final list, requiring agreement on each and every statement to increase group task identity and autonomy (Cohen et al. 1996). They should be careful to note said condition is not intended to impede individual voices (Gentile 2010), but rather to foster a sense of collective identity and firm-wide cohesion. Any residual disagreements can result in the removal of a particular statement.

The final pronouncement requires that the team prepare itself for the next phase, which involves intergroup negotiations, whereby codes of conduct continue to be refined. It is in stage three that teams will begin to experience significantly higher levels of conflict as they begin to interact with individuals operating within very different areas of the firm. In preparation, team members must solidify their joint commandments and insure that all statements are easy to understand and are clearly articulated. Working with moderators, teams should prepare for these discussions by explicating underlying rationales for items in ways that resonate with coworkers at or near their levels of operation. 


\section{Stage Three: Intergroup Negotiations}

Stage three will likely vary considerably in length and complexity, depending upon size and hierarchy in the focal company. It is at this stage that the independent groups begin their negotiations with other business units (e.g., marketing comes together with accounting) in continuing to develop and define the company relevant code of ethics. This third stage includes other requirements for success such as selection of a group leader to facilitate negotiations and the use of trained mediators.

As a result, teams assign one person to become spokesperson for the duration of discussions, with the remainder of the group acting as resources and support. Selection often occurs naturally as leaders are likely to emerge during the second stage (Smith and Foti 1998). This separation of duty facilitates greater organization and structure to the process, as discussions are likely to become increasingly heated and controversial; thus, trust in the designated leader clearly is essential (Bentele and Seidenglanz 2008). The second major difference in stage three is the introduction of trained mediators to the process. These third-party mediators are brought into work with the unit dyads to insure teams operate in the best interests of their collectives and to navigate away from idiosyncratic priorities.

The process begins with teams having an opportunity to read and discuss the lists of those they are negotiating with and make comparisons to their pronouncements. The goal is to create three smaller lists outlining those of (a) clear agreement, (b) significant difference, and (c) little perceived concern. Once these lists are determined, conversations with mediators once again introduce issues advocated by Werhane et al. More depth is given to possible positive and negative consequences of their combined actions, emphasizing the biological modeling of Frederick $(1995,1998)$. A relevant analogy mimics the image of a stone dropped in the middle of a calm pool of water, watching concentric circles as they ripple throughout the entire area until reaching the shoreline. As the groups enter discussions regarding their codes of significant difference, participants are asked to consider each ethical mandate as a circle representing potential systemic impact on the variety of internal and external stakeholders (see Clarkson 1995). Their task is to insure that ethical parameters that emerge from negotiations are reflective of this impact.

Role of Mediator The two units interact on-and-off until a resolution is reached that is agreed upon by both groups of team members. These negotiations are the most difficult of the process and require the greatest amount of intervention by the mediator. Both groups involved in this discussion are likely to hold priorities consistent with their work unit; it is the mediator's job to bring consensus and understanding between the groups. The interventional methods employed by mediators will likely include three primary techniques through duration of the discussions: (1) the development of key negotiable points for each party (Munro 1997), (2) educating and advising adversarial team members, and (3) encouraging concessions (Wall et al. 2001).

While it is not the role of the mediator to make decisions for the group, such third-party consultation is necessary for smoothing arguments, generating understanding, and building trust between constituents (Landau and Landau 1997). As the two groups in discussion are often operating from a list of priorities derived from specific work-units, arguments are likely to arise surrounding perceived importance of items placed in the collective code of ethics. Accordingly, mediators are expected to utilize communicative (McAllister 1998) and solution-based (Conlon and Fasolo 1990) expertise to bring about a joint understanding and develop newly-framed, collaborative items that satisfy involved parties (Kaufman and Duncan 1992). These processes encourage workers to seek an end result consistent with the quality output of earlier stages. In addition, it should build confidence that the final product is an employee-driven set of ethics.

\section{Stage Four: Board Endorsement}

Once all work-units have come to an agreement on their corporate code of ethics, the process progresses into the fourth stage-board endorsement. This final step in the bottom-up process is the most integrating stage of the four, as it entails the culmination of all prior work and requires buy-in of the top executives in the firm and board of directors' approval. In some cases, organizations may be small enough or privately held and not be subject to intense scrutiny experienced within large public corporations; however, every organization has owners, employees, and a variety of key external stakeholders who have vested interests in the conduct of the company that must play a vital role in the decision-making elements of the firm.

Given the complexity of navigating relationships with senior leadership, directives in stage four are drawn from the scholarship on Leader-Member Exchange Theory. As such, we recognize inherent difficulties employee members of an organization are likely to face when interacting with members of senior management (Bauer and Green 1996), and apply related tenets for navigating board approval.

Choice of Representatives The first task is to assemble a team of representatives from the various business units who will be responsible for both presenting and defending the code of ethics to the board (designated by 
letters in Fig. 1). The decision of who represents their interests within stage four is different from stage three; while representatives in stage three emerge due to inherent leadership qualities, representatives in stage four must be chosen according to their relationships with members of senior management (Dienesch and Liden 1986; Graen and Uhl-Bien 1995). Choosing individuals that have prior experience successfully interacting with senior leadership in the organization engenders the highest levels of trust (Bauer and Green 1996), as such relationships are developed over time and are based on continuous proof of both ability and performance (Mayer et al. 1995). Accordingly, prior developed trust and responsibility between a subordinate and senior-level employee provides for fertile grounding in understanding and acceptance (McAllister 1995).

Trust in leader-member relationships is integral for engaging senior management, corporate executives, and the board, as the bottom-up process of developing an influential corporate code is likely to be faced with questions and doubts. In placing organizational employees that have proven commitment to/understanding of organizational operations and dynamics in front of the board increases overall negotiation power of lower-level employees (Westphal 1999). Thus, key decision makers are more likely to engage in, listen to, and approve the presented code of ethics when interacting with individuals that have an established level of working together for goal attainment (Turner 1990).

Prior to board presentation, lower-level representatives should work collectively with the larger contingent to identify key supporting discussion points for items in the code. It should be disseminated to all employees to allow for final review and feedback. Since the group of representatives come from diverse positions within the firm, and have been actively engaged with the complete membership of the company, they are in an excellent position to seek input from coworkers. Once voices of the rank and file are heard, representatives may prepare arguments and presentations for the board.

Presentation to Board The presentation before the board of directors or advisory body should take place at a meeting dedicated to the task of review without their being encumbered by other responsibilities. In addition, the best location is the premises of the firm so that as many workers as can or wish to attend are there. If the company is too large or the facility does not contain a room that will accommodate such an audience, a minimum of all senior management, representatives, and board members must be present. Materials should be distributed to the board prior to this meeting to provide for sufficient time to review and question its development and content.
Compared to stage three, negotiation does not play a significant role in this phase of the bottom-up process. Rather, the presentation is structured as an informational defense with representatives supporting their work and addressing any clarifying issues brought to light by organizational officials. While clarifying questions can be asked, the primary responsibility of this body is to insure the appropriateness and completeness of this moral foundation rather than introducing new ideas or criticizing individual tenets. Since the purpose of using a bottom-up approach is to develop a code of ethics representative of all levels of the organization, members of the board may not exert influence or make major changes, though they may play a role in modifications surrounding appropriate verbiage.

If approval is granted, the internal or external legal representatives must pass judgment before the code of conduct becomes the official ethical guide. Recent scandals involving large public companies like Enron have led to legislation such as Sarbanes-Oxley, with additional laws and consumer protection on the horizon because of the more recent financial meltdown. Thus, it is important to insure that these moral prescriptions are in concert with the compliance requirements of legal tenets.

\section{Considerations for a Bottom-Up Approach}

The processes associated with a bottom-up approach to developing a code of ethics are presented in their entirety. Several concerns that may arise, however, warrant further discussion; the most fundamental of those involving time commitment and disruption of work as well as organizational size.

\section{Time Commitment and Disruption to Work Flow}

When presented in its entirety, the expected timeline from start to finish may be viewed as a daunting series of tasks that take away precious hours from more ordinary responsibilities. While employees will understand the value of these deliberations, they may also be wary of what is a major time commitment, involving activities not directly supported by principal goal structures of management. Exacerbating this perspective is one's history with prior organizations-either through personal interactions with senior management or prior involvement with codes of ethics development - that emphasized alternative perspectives (e.g., top-down) than the one offered here. Since a bottom-up approach presents a unique model of involvement, it is unlikely that all employees will feel comfortable allowing such defused levels of control in a crucial corporate doctrine. 
Accordingly, top management must express their dedication to the process and a commitment to allocating the necessary time (see McNamee and Fleming 2007), with several pronouncements to insure widespread perceptions of sincerity. First, executive level management should reveal their expectations and understanding that the developed code of ethical conduct will be of the people, with their managerial role a complementary one of overview and support. Second, leadership should be open to embracing the final result, placing importance on a workercentered, problem resolution result (Sabatier 1986). Finally, management should help employees deal with disruptions to regular assignments, even relieving them from nonessential tasks.

\section{Organizational Size}

While debate exists over the relationship between size and complexity (see Beyer and Trice 1979 for an historical example), there should be little doubt about the magnitude of the challenges in developing a code of ethics in large, multinational firms. Differences in cultures, legal systems, dominant religious beliefs, and population diversity may have the same impact on the development of the moral fabric of an organization as they do on its performance (Kim and Mauborgne 1987). Problems occur with translations of instructions into different languages, variations in work product across units, and assimilation of resulting codes into a single, globally applicable document. These dilemmas may be even more vexing if there is animosity among divisions or if they are only loosely aligned (see Almond and Ferner 2006).

The best solution is to define the reach of a particular set of codes in as small a portion of a large company as possible. While it is a rough yardstick, any unit that encapsulates the full set of business functions (e.g., operations, marketing, accounting, etc.), has an individual or autonomous website that characterizes it as serving consumer needs in their entirety, and/or has a substantial set of stakeholders not relevant to other portions of the parent company, may be eligible for a separate ethical code. When each of the independent analyses are completed and approved by their boards, representatives from each system, should then come together to develop a global set of moral parameters reflective of the entire conglomerate. From here, stages three and four will be repeated, with the use of mediation to supplement cross-company/cross-cultural negotiations.

\section{Closing Remarks}

While the option exists for implementing either a top-down or bottom-up approach in the development of ethical codes of conduct, our discussion makes it clear that the cooperation of workers at all levels is necessary for appropriate development and implementation of a new code. Even bottom-up practices cannot be successful without enthusiastic support from senior leadership, along with real ownership of the processes and outcomes among individuals and their groupings (McNamee and Fleming 2007). The management task is to energize workers' collective sense of self so that they realize how their personal ethics and shared more impact themselves and the larger entity (Jones et al. 2007). The goal ultimately is to influence the corporate culture and formal structure of firms in ways that shape managerial behavior and employee actions toward a moral ideal (Murphy 1988). Such results eventually create an environment, whereby leadership understands how to recognize and reward ethical behaviors and to ferret-out and punish unethical conduct across all layers in the company (Trevino et al. 2000).

Our bottom-up perspective allows organizational workers to exert influence over the final code of ethics and let's their voices be heard. Instead of privileging one position relative to others, an attempt is made to even the playing field, allowing employees at all levels in the company hierarchy to explore and refine ethical beliefs without constraints associated with status or reporting structure. As a consequence, they are free to seek a higher moral ground reflective of individual values, as well as job functions. They must come together to summarize their statements across the entire business, but this step is completed without predetermined ordering of preferences or people. The goal is for employees to recognize that the end result is equally shared among them.

The rationales, processes, and issues presented herein have a taken-for-granted quality. They assume that managers desire to rise to higher moral ground over time, with an emphasis on employee participation to resolve systemic challenges. This perspective clearly is not the orientation of all companies, as the lack of ethics in recent infractions suggests. Nevertheless, the majority of organizations and workers do wish to conduct themselves in ways that build trust with stakeholders, if only because it serves their longterm interests for survival and profitability. When given the opportunity to do so using techniques that rely on selfreflection and individual input, we believe that chances of arriving at widely-accepted codes of conduct increase greatly. Our hope is that this method can help managers to reach new heights of moral maturity.

\section{References}

Almond, P., \& Ferner, A. (2006). American multinationals in Europe: Managing employment relations across national borders. Oxford: Oxford University Press. 
Andrews, K. (Ed.). (1989). Ethics in practice: Managing the moral corporation. Boston: Harvard Business Press.

Ashforth, B. E., \& Anand, V. (2003). The normalization of corruption in organizations. In R. M. Kramer \& B. M. Staw (Eds.), Research in organizational behavior (Vol. 25, pp. 1-52). Oxford: Elsevier.

Badaracco, J. L., \& Webb, A. P. (1995). Business ethics: A view from the trenches. California Management Review, 37, 8-28.

Bauer, T. N., \& Green, S. G. (1996). Development of leader-member exchange: A longitudinal test. The Academy of Management Journal, 39, 1538-1567.

Bentele, G., \& Seidenglanz, R. (2008). Trust and credibilityPrerequisites for communication management. In A. Zerfass, B. van Ruler, \& K. Sriramesh (Eds.), Public relations research (pp. 49-62). Wiesbaden: VS für Sozialwissenschaften.

Beyer, J. M., \& Trice, H. M. (1979). A reexamination of the relation between size and various components of organizational complexity. Administrative Science Quarterly, 24, 48-64.

Brakel, A. (2007). The moral standard of a company: Performing the norms of moral codes. International Journal of Business Governance and Ethics, 3, 95.

Buchholz, R. A., \& Rosenthal, S. B. (2001). A philosophical framework for case studies. Journal of Business Ethics, 29, $25-31$.

Chonko, L. B., Wortuba, T. R., \& Loe, T. W. (2002). Direct selling ethics at the top: An industry audit and status report. Journal of Personal Selling and Sales Management, 22, 87-95.

Clarkson, M. B. E. (1995). A stakeholder framework for analyzing and evaluating corporate social performance. Academy of Management Review, 20, 92-117.

Cohen, S. G., Ledford, G. E., \& Spreitzer, G. M. (1996). A predictive model of self-managing work team effectiveness. Human Relations, 49, 643-676.

Conlon, D. E., \& Fasolo, P. M. (1990). Influence of speed of thirdparty intervention and outcome on negotiator and constituent fairness judgments. Academy of Management Journal, 33, 833-846.

de Colle, S., \& Werhane, P. H. (2008). Moral motivation across ethical theories: What can we learn for designing corporate ethics programs? Journal of Business Ethics, 81, 751-764.

De Wever, B., Van Winckel, M., \& Valcke, M. (2008). Discussing patient management online: The impact of roles on knowledge construction for students interning at the paediatric ward. Advances in Health Sciences Education, 13(1), 25-42.

Dienesch, R. M., \& Liden, R. C. (1986). Leader-member exchange model of leadership: A critique and further development. Academy of Management Review, 11, 618-634.

DuFrene, D. D. (2001). The external ethics audit: A guided experience in self-directed web inquiry. Teaching Business Ethics, 5, 71-77.

Elango, B. B., Paul, K., Kundu, S., \& Paudel, S. (2010). Organizational ethics, individual ethics, and ethical intentions in international decision-making. Journal of Business Ethics, 97, 543-561.

Enderle, G. (1996). Towards business ethics as an academic discipline. Business Ethics Quarterly, 6, 43-65.

Feldman, S. P. (2007). Moral memory: Why and how moral companies manage tradition. Journal of Business Ethics, 72, 395-409.

Fisher, R. J. (1972). The problem-solving workshop in conflict resolution. In R. L. Merritt (Ed.), Communication in international politics (pp. 168-204). Urbana: University of Illinois Press.

Fisher, R. J. (1983). Third party consultation as a method of intergroup conflict resolution a review of studies. Journal of Conflict Resolution, 27(2), 301-334.
Frederick, W. C. (1995). Values, nature, and culture in the American corporation. New York: Oxford University Press.

Frederick, W. C. (1998). Creatures, corporations, communities, chaos, complexity. Business and Society, 37, 358-389.

Frederick, W. C. (2006). Corporation, be good!. Indianapolis, IN: Dog Ear Publishing.

Garcia-Marza, D. (2005). Trust and dialogue: Theoretical approached to ethics auditing. Journal of Business Ethics, 57, 209-219.

Gentile, M. C. (2010). Giving voice to values: How to speak you're mind when you know it's right. New Have: Yale University Press.

Geva, A. (2006). A typology of moral problem in business: A framework for ethical management. Journal of Business Ethics, 69, 133-147.

Gilbert, J. A., Stead, B. A., \& Ivancevich, J. M. (1999). Diversity management: A new organizational paradigm. , 21, 61-76.

Gopalakrishnan, S., Mangaliso, M. P., \& Butterfield, D. (2008). Managing ethically in times of transformation. Group and Organization Management, 33, 756-759.

Gower, K. K. (2003). Legal and ethical restraints on public relations. Prospect Heights, IL: Waveland Press.

Graen, G. B., \& Scandura, T. A. (1987). Toward a psychology of dyadic organizing. Research in Organizational Behavior, 9, 175-208.

Graen, G. B., \& Uhl-Bien, M. (1995). Development of LMX theory of leadership over 25 years: Applying a multi-level-multi-domain perspective. Leadership Quarterly, 6, 210-247.

Hill, R. P., Ainscough, T., Shank, T., \& Manullang, D. (2007). Corporate social responsibility and socially responsible investing: A global perspective. Journal of Business Ethics, 70, $165-174$.

Hill, R. P., \& Watkins, A. (2009). The profit implications of altruistic versus egoistic orientations for business-to-business exchanges. International Journal of Research in Marketing, 26, $52-59$.

Jones, T. M., Felps, W., \& Bigley, G. A. (2007). Ethical theory and stakeholder-related decisions: The role of stakeholder culture. Academy of Management Review, 32, 137-155.

Kaufman, S., \& Duncan, G. T. (1992). A formal framework for mediator mechanisms and motivations. Journal of Conflict Resolution, 36, 688-708.

Kim, W. C., \& Mauborgne, R. A. (1987). Cross-cultural strategies. Journal of Business Strategy, 7, 28-35.

Kok, P., van de Wiele, T., McKenna, R., \& Brown, A. (2001). A corporate social responsibility audit within a quality management framework. Journal of Business Ethics, 31, 285-297.

Kruckeberg, D. (2000). The public relations practitioner's role in practicing strategic ethics. Public Relations Quarterly, 45(3), 35-39.

Landau, D., \& Landau, S. (1997). Confidence-building measures in mediation. Mediation Quarterly, 15, 97-103.

Martin, K. D., \& Cullen, J. B. (2006). Continuities and extensions of ethical climate theory: A meta-analytic review. Journal of Business Ethics, 69, 175-194.

Martin, J. A., \& Eisenhardt, K. M. (2010). Rewiring: Cross-businessunit collaborations in multibusiness organizations. Academy of Management Journal, 53, 265-301.

Mayer, R. C., Davis, J. H., \& Schoorman, F. D. (1995). An integrative model of organizational trust. Academy of Management Review, 20, 709-734.

McAllister, D. J. (1995). Affect- and cognitive-based trust as foundations for interpersonal cooperation in organizations. Academy of Management Journal, 38, 24-59.

McAllister, J. F. O., (1998). Inside Wye Plantation. Time, 2, pp. $38-44$. 
McNamee, M. J., \& Fleming, S. (2007). Ethics audits and corporate governance: The case of public sector sports organizations. Journal of Business Ethics, 73, 425-437.

Munro, J. D. (1997). Using unconditionally constructive mediation to resolve family-system disputes related to persons with disabilities. Families in Society, 78, 609-616.

Murphy, P. E. (1988). Implementing business ethics. Journal of Business Ethics, 7, 907-915.

Nash, L. L. (1981). Ethics without the sermon. Harvard Business Review, 59, 79-90.

Nielsen, R. P., \& Massa, F. G. (2013). Reintegrating ethics and institutional theories. Journal of Business Ethics, 115, 135-147.

Nurmi, J. E. (1993). Adolescent development in an age-graded context: The role of personal beliefs, goals, and strategies in the tackling of developmental tasks and standards. International Journal of Behavioral Development, 16(2), 169-189.

O'Fallon, M. J., \& Butterfield, K. D. (2005). A review of the empirical ethical decision-making literature: 1996-2003. Journal of Business Ethics, 59, 375-413.

Rawls, J. (1971). A theory of justice. Cambridge, MA: Harvard University Press.

Rosthorn, J. (2000). Business ethics auditing-More than a stakeholder's toy. Journal of Business Ethics, 27, 9-19.

Sabatier, P. A. (1986). Top-down and bottom-up approaches to implementation research: A critical analysis and suggested synthesis. Journal of public policy, 6(01), 21-48.

Sanderson, G. R., \& Varner, I. I. (1984). What's wrong with corporate codes of conduct?'. Management Accounting, 66(1), 28-31.

Schwartz, M. S. (2002). A code of ethics for corporate code of ethics. Journal of Business Ethics, 41, 27-43.

Smith, J. A., \& Foti, R. J. (1998). A pattern approach to the study of leader emergence. Leadership Quarterly, 9, 147-160.

Stark, A. (1993). What's the matter with business ethics? Harvard Business Review, 71, 38-48.

Stevens, B. (2008). Corporate ethical codes: Effective instruments for influencing behavior. Journal of Business Ethics, 78(4), 601-609.
Strijbos, J. W., Martens, R. L., Jochems, W., \& Broers, N. J. (2004). The effect of functional roles on group efficiency: Using multilevel modelling and content analysis to investigate computer-supported collaboration in small groups. Small Group Research, 35, 195-229.

Trevino, L. K., Hartman, L. P., \& Brown, M. (2000). Moral person and moral manager: How executives develop a reputation for ethical leadership. California Management Review, 42, 128-142.

Treviño, L. K., \& Weaver, G. R. (2003). Managing ethics in business organizations. Stanford, CA: Stanford Business Books.

Treviño, L. K., Weaver, G., \& Reynolds, S. J. (2006). Behavioral ethics in organizations: A review. Journal of Management, 32, 951-990.

Turner, D. B. (1990). Intraorganizational bargaining: The effect of goal congruence and trust on negotiator strategy use. Сотmunication Studies, 41(1), 54-75.

Uhl-Bien, M., Marion, R., \& McKelvey, B. (2007). Complexity leadership theory: Shifting leadership from the industrial age to the knowledge era. The Leadership Quarterly, 18, 298-318.

Wall, J. A., Stark, J. B., \& Standifer, R. L. (2001). Mediation a current review and theory development. Journal of Conflict Resolution, 45(3), 370-391.

Werhane, P. H. (2002). Moral imagination and systems thinking. Journal of Business Ethics, 38, 33-42.

Westphal, J. D. (1999). Collaboration in the boardroom: Behavioral and performance consequences of CEO-board social ties. Academy of Management Journal, 42, 7-24.

Wheelan, S. A. (2009). Group size, group development, and group productivity. Small Group Research, 40, 247-262.

Zadek, S. (1998). Balancing performance, ethics, and accountability. Journal of Business Ethics, 17, 1421-1441.

Zaheer, A., McEvily, B., \& Perrone, V. (1998). Does trust matter? Exploring the effects of interorganizational and interpersonal trust on performance. Organization Science, 9(2), 141-159. 
Reproduced with permission of the copyright owner. Further reproduction prohibited without permission. 